\title{
Tumour Associated Tissue Eosinophilia as a Prognostic Indicator in Squamous Cell Carcinoma of Upper Aerodigestive Tract
}

\author{
Chandra Bhan, Kartikeya Purohit, Jagdish Prasad Purohit, Ajay Pratap Singh, \\ Bhoopendra Singh, Siva Selvaraj, Manish Pandey, Vineet Kumar \\ Department of ENT, Head and Neck Surgery, MLB Medical College, Jhansi, India \\ Email: chandrabhan.prajapati@gmail.com
}

Received 27 August 2015; accepted 5 March 2016; published 8 March 2016

Copyright (C) 2016 by authors and Scientific Research Publishing Inc.

This work is licensed under the Creative Commons Attribution International License (CC BY). http://creativecommons.org/licenses/by/4.0/

(c) (i) Open Access

\begin{abstract}
Immune response is known to develop against malignant tumours. Malignant tumours express newer antigen on their cell surface membrane which elicit immunological reaction in and around tumoural tissue. In early part of immune reaction neutrophil, eosinophil migrates followed by monocyte-macrophage cell. Tumor associated tissue eosinophilia (TATE) is believed to play a significant role in the biological behavior of the carcinoma. Eosinophil infiltrate in association with the head and neck squamous cell carcinoma (SCC) have been reviewed from time-to-time. The significance of such an association has been variably thought to be either a potential diagnostic tool for stromal invasion or as a prognostic indicator. The aim of this study was to investigate and evaluate the possible role of the tumour associated tissue eosinophilia (TATE) as a predictive indicator for the grading and establishing prognosis of the upper aerodigestive tract squamous cell carcinoma (SCC).
\end{abstract}

\section{Keywords}

Tumour Associated Tissue Eosinophilia (TATE), Squamous Cell Carcinoma (SCC)

\section{Introduction}

Inflammatory infiltration with eosinophil as a result of immune reaction against tumour antigen in or around the tumoural tissue varies among the cases with squamous cell carcinoma (SCC) of upper aero digestive tract. The aim of this study was to investigate and evaluate the possible role of the tumour associated tissue eosinophilia (TATE) as a predictive indicator for the grading and establishing prognosis of the upper aerodigestive tract

How to cite this paper: Bhan, C., Purohit, K., Purohit, J.P., Singh, A.P., Singh, B., Selvaraj, S., Pandey, M. and Kumar, V. (2016) Tumour Associated Tissue Eosinophilia as a Prognostic Indicator in Squamous Cell Carcinoma of Upper Aerodigestive Tract. International Journal of Otolaryngology and Head \& Neck Surgery, 5, 54-58. http://dx.doi.org/10.4236/ijohns.2016.52009 
squamous cell carcinoma (SCC).

In our study 58 cases of squamous cell carcinoma involving oral cavity, pharynx and larynx except nose and nasopharynx were biopsied in department of ENT and Head, Neck Surgery, MLB Medical College, Jhansi (INDIA) for the evaluation of tumour associated tissue eosinophilia. The study is based on the tissue eosinophil count per 10 high power field and cases were grouped into 3 GRADES-I, II and III.

Various parameters were taken to establish possible prognostic indicators for squamous cell carcinoma. Clinically the most significant indicators are TNM classification and lymph node metastasis classification [1] [2]. Predictive histopathologic parameters are borders of tumour and grading of the tumour and cytological parameter in predicting the prognosis is tumour associated tissue eosinophilia [1] [2]. The tumour with pushing border and broad cords of cells have better prognosis whereas tumours which invade as single cells or small irregular cords (non-pushing) have relatively poor prognosis [3].

Squamous cell carcinoma is classified into 3 histopathological grades-well differentiated, moderately differentiated and poorly differentiated based on nuclear atypia and keratinisation [4]. Tissue eosinophilia is known to be associated with a number of neoplasm's [5].

Clinical correlative studies of patients with tissue eosinophilia have suggested that tissue eosinophilia can be protective in tumours and plays as a good prognostic indicator [5]. The study demonstrated positive correlation between the tumours associated tissue eosinophilia and the prognosis of the cancer.

\section{Methods and Materials}

All the patients under study were biopsied after taking informed consent and detailed history and clinical examination. Histopathological specimen was studied regarding differentiation of tumour, infiltration of eosinophil and nature of borders. Tissue eosinophils were counted in randomly chosen 10 high power field in slides prepared with haematoxylin and eosin staining and were classified into three GRADES:

\begin{tabular}{cc}
\hline Grades & Eosinophils count \\
\hline I & $0-20$ eosinophils $/ 10 \mathrm{hpf}$ \\
II & $21-40$ eosinophils $/ 10 \mathrm{hpf}$ \\
III & More than 41 eosinophils $/ 10 \mathrm{hpf}$ \\
\hline
\end{tabular}

Tumour associated tissue eosinophilia correlate with the immune status of the patient. Patient with better immune status shows better cellular immune reaction to tumour and leads to more infiltration of eosinophils and points towards favourable prognosis. Biopsied specimens were also examined for the nature of the borders and cords. Borders are classified into the following types:

1) Large pushing borders and broad cords (pushing border)

2) Borders invading as single cell or small cords (non-pushing border)

Squamous cell carcinoma is also classified into 3 grades based on the degree of keratinisation and nuclear atypia namely:

1) Well differentiated SCC

2) Moderately differentiated SCC

3) Poorly differentiated SCC

In our study, the histopathological findings like borders, grading and cytological indicator tumour associated tissue eosinophilia were analysed as prognostic indicator for the squamous cell carcinoma of upper aero digestive tract including oral cavity, pharynx and larynx except nose and nasopharynx.

\section{Observation}

The biopsied specimens of 58 patients having squamous cell carcinoma of upper aerodigestive tract including oral cavity, pharynx and larynx except nose and nasopharynx were studied. Out of them 50 were male and 8 were female with the male: female was 6:1, belonged to the age group ranging from 25 years to 80 years (Table 1).

35 (60.34\%) cases were having oral cavity SCC, 13 (22.41\%) cases were having pharynx SCC and 10 (17.24\%) cases were having larynx SCC (Table 2). 
Table 1. Showing distribution of sex among cases.

\begin{tabular}{ccc}
\hline Sex & No of cases & Percentage \\
\hline Male & 50 & $86.20 \%$ \\
Female & 08 & $13.80 \%$ \\
\hline
\end{tabular}

Table2. Showing distribution of site among cases.

\begin{tabular}{ccc}
\hline Site & No of cases & Percentage \\
\hline Oral cavity & 35 & $60.34 \%$ \\
Pharynx & 13 & $22.41 \%$ \\
Larynx & 10 & $17.24 \%$ \\
\hline
\end{tabular}

In our study 23 cases were having well differentiated SCC, 32 were having moderately differentiated SCC and 3 cases were having poorly differentiated SCC. All 23 cases with well differentiated SCC were having pushing borders, 2 were having grade I TATE, 6 were having grade II TATE and 15 were having grade III TATE. All 32 cases with moderately differentiated SCC were having pushing borders, 5 were having grade I TATE, 22 were having grade II TATE and 5 were having grade III TATE. All 3 cases with poorly differentiated SCC were having non pushing borders and grade I TATE (Table 3).

\section{Discussion}

Leighton defined TATE as the "tumoral infiltration by eosinophils not related to the presence of necrosis and/or ulceration"; although, the definition was arbitrary and poorly defined.

The studies by Goldsmith et al., in 1987 [6] and in 1992 [7], Thompson et al., in 1994 [8], Nielsen et al., in 1999 [9], Fernández Aceñero et al., in 2000 [10] and Dorta et al., in 2002 have established TATE with a favourable prognosis while the studies by Horiuchi et al., in 1993 [11], Van Driel et al., in1999 [12] and Wong et al., in 1999 [13] were associated with an unfavourable prognosis of TATE and some studies like Looi, in 1987 [14]; Sassler et al., in 1995 [15] have shown no influence on the prognosis.

In the head and neck SCC, it has been reported that the presence of tissue eosinophils ranges from $22 \%$ to 89\%. According to Said M, Wiseman S, Yang J, Alrawi S, Douglas W, Cheney R, et al. TATE is a tissue morphologic marker for assessing stromal invasion in laryngeal squamous neoplasms. In our study, TATE was present in 86\% (43 out of 50) cases, which is in accordance with other studies. Deron et al. in their study to evaluate TATE kept the cut-off of eosinophil infiltration at 2 eos/hpf [16]. Goldsmith et al., in their study, segregated eosinophilic infiltration within 4 categories of progressive increasing count, the highest being categorized as 4+, that is, more than 30 eos/hpf [6] [7]. Said et al. in their study, evaluated 87 cases of invasive SCC and preinvasive squamous neoplasia and segregated the elevated eosinophils as: Focally and moderately elevated (59 eos/hpf), focally and markedly increased (>10/hpf), diffusely and moderately elevated (519 eos/10 hpf) and diffusely and markedly increased (>20/10 hpf) [17].

In our study, we categorized and graded the elevated eosinophil count as I with 0 - 20 cells/10 hpf, II with 21 - 40 cells/10 hpf and III with more than 40 cells/10 hpf. Amirala Aghbali et al. in their study on Tumour-associated Tissue and Blood Eosinophils in Oral Squamous Cell Carcinoma found that Eosinophil counts in tissue samples revealed positive correlation with tumour grade without positive relation with tumour size and lymph node involvement. These findings are consistent with some studies and in contrast to some others. Priya Shirish Joshi et al. underwent histochemical study of tissue eosinophilia in oral squamous cell carcinoma using Congo red staining showed $36(83.72 \%)$ cases were found to have elevated diffuse eosinophilic infiltration out of which 21 (48.83\%) were severely elevated, 13 (30.23\%) were moderately elevated and 2 (4.65\%) were mildly elevated. Only 7 (16.27\%) cases showed focal eosinophilic infiltration out of which 4 were severely elevated and 3 were mildly elevated.

In our current study, we classified the TATE infiltration into three grades I, II and III and the number of cases showing grade I is 10 (17.2\%), grade II is 28 (48.3\%) and grade III is 20 (34.5\%). Our study also shows with advancing age patient immune status become poorer and TATE declines. 
Table 3. Showing differentiation of tumour and histological parameter.

\begin{tabular}{ccccc}
\hline Differentiation of tumour & Pushing border & \multicolumn{3}{c}{ Grade of TATE } \\
\cline { 3 - 5 } & & I & II & III \\
\hline Well differentiated (23) & 23 & 02 & 06 & 15 \\
Moderately differentiated (32) & 32 & 05 & 22 & 05 \\
Poorly differentiated (03) & 00 & 03 & 00 & 00 \\
TOTAL = 58 & $\mathbf{5 5}$ & $\mathbf{1 0}$ & $\mathbf{2 8}$ & $\mathbf{2 0}$ \\
\hline
\end{tabular}

\section{Conclusions}

$>$ Incidence of SCC of upper aerodigestive region is more in male as compared to female.

$>$ Oral cavity is the most common site of SCC of upper aerodigestive region.

Pushing border and higher eosinophil count were associated with favourable prognosis.

\section{References}

[1] Barnes, L., Everson, J.W., Reichart, P. and Sidransky, D. (2005) WHO Classification of Tumours. Pathologyand Genetics of Head and Neck Tumors. IARC Press, Lyon, 109-121.

[2] Ercan, I., Cakir, B., Başak, T., Ozdemir, T., Sayin, I. and Turgut, S. (2005) Prognostic Significance of Stromal Eosinophilic Infiltration in Cancer of the Larynx. Otolaryngology_-Head and Neck Surgery, 132, 869-873. http://dx.doi.org/10.1016/j.otohns.2005.01.041

[3] Crissman, J.D. and Zarbo, R.J. (1989) Dysplasia, in Situ and Progression to Invasive Squamous Cell Carcinoma of the Upper Aerodigestive Tract. The American Journal of Surgical Pathology, 13, 5-16.

[4] Roland, N.J., Caslin, A.W., Nash, J. and Stell, P.M. (1992) Value of Grading Squamous Cell Carcinoma of the Head and Neck. Head \& Neck, 14, 224-229. http://dx.doi.org/10.1002/hed.2880140310

[5] Spry, C. (1989) Eosinophils. Oxford University Press, New York.

[6] Goldsmith, M.M., Cresson, D.H. and Askin, F.B. (1987) The Prognostic Significance of Stromal Eosinophilia in Head and Neck Cancer. Otolaryngology-Head and Neck Surgery, 96, 319-324. http://dx.doi.org/10.1177/019459988709600403

[7] Goldsmith, M.M., Belchis, D.A., Cresson, D.H., Merritt 3rd, W.D. and Askin, F.B. (1992) The Importance of the Eosinophil in Head and Neck Cancer. Otolaryngology_Head and Neck Surgery, 106, 27-33.

[8] Thompson, A.C., Bradley, P.J. and Griffin, N.R. (1994) Tumor-Associated Tissue Eosinophilia and Long-Term Prognosis for Carcinoma of the Larynx. The American Journal of Surgery, 168, 469-471. http://dx.doi.org/10.1016/S0002-9610(05)80102-3

[9] Nielsen, H.J., Hansen, U., Christensen, I.J., Reimert, C.M., Brünner, N. and Moesgaard, F. (1999) Independent Prognostic Value of Eosinophil and Mast Cell Infiltration in Colorectal Cancer Tissue. The Journal of Pathology, 189, 487495. http://dx.doi.org/10.1002/(SICI)1096-9896(199912)189:4<487::AID-PATH484>3.0.CO;2-I

[10] Fernández-Aceñero, M.J., Galindo-Gallego, M., Sanz, J. and Aljama, A. (2000) Prognostic Influence of TumorAssociated Eosinophilic Infiltrate in Colorectal Carcinoma. Cancer, 88, 1544-1548. http://dx.doi.org/10.1002/(SICI)1097-0142(20000401)88:7<1544::AID-CNCR7>3.0.CO;2-S

[11] Horiuchi, K., Mishima, K., Ohsawa, M., Sugimura, M. and Aozasa, K. (1993) Prognostic Factors for Well-Differentiated Squamous Cell Carcinoma in the Oral Cavity with Emphasis Onimmunohistochemical Evaluation. Journal of Surgical Oncology, 53, 92-96. http://dx.doi.org/10.1002/jso.2930530209

[12] van Driel, W.J., Hogendoorn, P.C., Jansen, F.W., Zwinderman, A.H., Trimbos, J.B. and Fleuren, G.J. (1996) TumorAssociated Eosinophilic Infiltrate of Cervical Cancer Is Indicative for a Less Effective Immune Response. Human Pathology, 27, 904-911. http://dx.doi.org/10.1016/S0046-8177(96)90216-6

[13] Wong, D.T., Bowen, S.M., Elovic, A., Gallagher, G.T. and Weller, P.F. (1999) Eosinophil Ablation and Tumor Development. Oral Oncology, 35, 496-501. http://dx.doi.org/10.1016/S1368-8375(99)00023-8

[14] Looi, L.M. (1987) Tumor Associated Tissue Eosinophilia in Nasopharyngeal Carcinoma. A Pathologic Study of 422 Primary and 138 Metastatic Tumors. Cancer, 59, 466-470. http://dx.doi.org/10.1002/1097-0142(19870201)59:3<466::AID-CNCR2820590319>3.0.CO;2-P

[15] Sassler, A.M., McClatchey, K.D., Wolf, G.T. and Fisher, S.G. (1995) Eosinophilic Infiltration in Advanced Laryngeal Squamous Cell Carcinoma. Laryngoscope, 105, 413-416. http://dx.doi.org/10.1288/00005537-199504000-00014 
[16] Deron, P., Goossens, A. and Halama, A.R. (1996) Tumour-Associated Tissue Eosinophilia in Head and Neck SquamousCell Carcinoma. ORL, 58, 167-170. http://dx.doi.org/10.1159/000276819

[17] Said, M., Wiseman, S., Yang, J., Alrawi, S., Douglas, W., Cheney, R., et al. (2005) Tissue Eosinophilia: A Morphologic Marker for Assessing Stromal Invasion in Laryngeal Squamous Neoplasms. BMC Clinical Pathology, 5, 1. 